\title{
Brain-derived neurotrophic factor is produced by skeletal muscle cells in response to contraction and enhances fat oxidation via activation of AMP-activated protein kinase
}

\author{
V. B. Matthews • M.-B. Åström • M. H. S. Chan • C. R. Bruce • K. S. Krabbe • \\ O. Prelovsek • T. Åkerström • C. Yfanti • C. Broholm • O. H. Mortensen • \\ M. Penkowa • P. Hojman • A. Zankari • M. J. Watt • H. Bruunsgaard • \\ B. K. Pedersen • M. A. Febbraio
}

Received: 25 February 2009 / Accepted: 16 March 2009/Published online: 22 April 2009

(C) Springer-Verlag 2009

\begin{abstract}
Aims/hypothesis Brain-derived neurotrophic factor (BDNF) is produced in skeletal muscle, but its functional significance is unknown. We aimed to determine the signalling processes and metabolic actions of BDNF.

Methods We first examined whether exercise induced $B D N F$ expression in humans. Next, C2C12 skeletal muscle cells were electrically stimulated to mimic contraction. L6 myotubes and isolated rat extensor digitorum longus muscles were treated with BDNF and phosphorylation of the proteins AMP-activated protein kinase (AMPK) $\left(\mathrm{Thr}^{172}\right)$ and acetyl coenzyme A carboxylase $\beta$ (ACC $\left.\beta\right)$ $\left(\mathrm{Ser}^{79}\right)$ were analysed, as was fatty acid oxidation (FAO).

V. B. Matthews and M.-B. Åström contributed equally to this study.

B. K. Pedersen and M. A. Febbraio co-directed this study.

Electronic supplementary material The online version of this article (doi:10.1007/s00125-009-1364-1) contains supplementary material, which is available to authorised users.

V. B. Matthews · M. H. S. Chan · C. R. Bruce · O. Prelovsek •

M. A. Febbraio $(\triangle)$

Cellular and Molecular Metabolism Laboratory, Diabetes and

Metabolism Division, Baker Heart Research Institute,

PO Box 6492, St Kilda Road Central,

Melbourne, VIC 8008, Australia

email: mark.febbraio@bakeridi.edu.au

M.-B. Åström • K. S. Krabbe · T. Åkerström • C. Yfanti •

C. Broholm • O. H. Mortensen · P. Hojman · A. Zankari •

H. Bruunsgaard $\cdot$ B. K. Pedersen $(\triangle)$

The Centre of Inflammation and Metabolism, Department of

Infectious Diseases and CMRC, Rigshospitalet-Section 7641,

Faculty of Health Sciences, University of Copenhagen,

Blegdamsvej 9,

2100 Copenhagen, Denmark

e-mail: bente.klarlund.pedersen@rh.regionh.dk
\end{abstract}

Finally, we electroporated a $B d n f$ vector into the tibialis cranialis muscle of mice.

Results BDNF mRNA and protein expression were increased in human skeletal muscle after exercise, but muscle-derived BDNF appeared not to be released into the circulation. Bdnf mRNA and protein expression was increased in muscle cells that were electrically stimulated. BDNF increased phosphorylation of AMPK and ACC $\beta$ and enhanced FAO both in vitro and ex vivo. The effect of BDNF on FAO was AMPK-dependent, since the increase in FAO was abrogated in cells infected with an AMPK dominant negative adenovirus or treated with Compound $\mathrm{C}$, an inhibitor of AMPK. Electroporation of a $B d n f$ expression

M. Penkowa

Section of Neuroprotection,

Institute of Neuroscience and Pharmacology,

the Panum Institute,

Faculty of Health Sciences,

University of Copenhagen,

Copenhagen, Denmark

M. J. Watt

Biology of Lipid Metabolism Group,

Department of Physiology,

Monash University,

Clayton, VIC, Australia 
vector into the tibialis cranialis muscle resulted in increased BDNF protein production and tropomyosin-related kinase $\mathrm{B}\left(\mathrm{TrkB}^{\mathrm{Tyr} 706 / 707}\right)$ and extracellular signal-regulated protein kinase ( $\mathrm{p} 44 / 42 \mathrm{Thr}^{202} / \mathrm{Tyr}^{204}$ ) phosphorylation in these muscles. In addition, phosphorylation of ACC $\beta$ was markedly elevated in the $B d n f$ electroporated muscles.

Conclusions/interpretation These data identify BDNF as a contraction-inducible protein in skeletal muscle that is capable of enhancing lipid oxidation in skeletal muscle via activation of AMPK.

Keywords Cytokines - Lipid metabolism - Metabolism · Neuropeptides $\cdot$ Physical activity

$\begin{array}{ll}\text { Abbreviations } \\ \text { ACC } \beta & \text { Acetyl coenzyme A carboxylase } \beta \\ \text { AICAR } & \text { 5-Aminoimidazole-4-carboxamide } \\ & \begin{array}{l}\text { 1- } \beta \text {-D-ribofuranoside } \\ \text { AMPK }\end{array} \\ \text { AMP-activated protein kinase } \\ \text { BDNF } & \text { Brain-derived neurotrophic factor } \\ \text { ERK } & \text { Extracellular signal-regulated protein kinase } \\ \text { FAO } & \text { Fatty acid oxidation } \\ \text { IHC } & \text { Immunohistochemistry } \\ \text { LDH } & \text { Lactate dehydrogenase } \\ \text { PCr } & \text { Phosphocreatine } \\ \text { rhBDNF } & \text { Recombinant human BDNF } \\ \text { TrkB } & \text { Tropomyosin-related kinase B }\end{array}$

\section{Introduction}

Regular physical activity is known to have multiple health benefits [1]. Of note, exercise is associated with increased insulin-stimulated glucose uptake in the immediate postexercise period [2, 3], while chronic physical activity enhances insulin sensitivity [4]. We have recently identified skeletal muscle as a cytokine-producing organ, demonstrating that the metabolic and physiological effects of exercise may also be mediated by skeletal muscle-derived humoral factors $[5,6]$. Skeletal muscles have the capacity to express a number of 'myokines' and it is now clear that IL-6 [7] and IL-8 [8] production is upregulated by muscle contraction and that these cytokines may be released from contracting skeletal muscle. Muscle-derived IL-6, but not IL-8, contributes markedly to systemic levels, where it works in a hormone-like fashion and plays an important role in lipid and glucose metabolism [9, 10], principally via activation of AMP-activated protein kinase (AMPK) [10]. Recent studies from others, employing skeletal muscle-specific AKT1 transgenic [11] and muscle-specific peroxisome proliferator activated receptor gamma coactivator 1 alpha (PGC-1 $\alpha$ ) knockout [12] mice, have also observed altered metabolism in tissues such as pancreas, liver and adipose tissue. The authors of these respective papers hypothesised that musclederived circulatory factors or myokines may have been responsible for the observed tissue cross-talk. Indeed, myokines are now recognised as a major contributing factor that links muscular activity with health [13].

Brain-derived neurotrophic factor (BDNF) is a member of the neurotrophic factor family that plays a key role in regulating survival, growth and maintenance of neurons [14]. It is also known that BDNF reduces food intake and lowers blood glucose in genetically modified $(\mathrm{db} / \mathrm{db})$ obese mice [15-18]. It is clear, therefore, that BDNF plays a role in both neurobiology and metabolism. Recent studies have demonstrated that physical exercise can increase circulating BDNF levels in both healthy humans $[19,20]$ and patients with multiple sclerosis [21], although the cellular origin of this increase is unclear. There are some reports in rodents showing that $B d n f$ mRNA increases in skeletal muscle in response to contraction [22, 23], but these studies suggested that the source of the BDNF was neurons within the skeletal muscle beds. However, in a recent study, Bdnf mRNA was shown to be expressed in murine skeletal muscle and was increased by inhibition of histone deacetylases [24]. Since exercise can inhibit histone deacetylases [25], the possibility exists that the increase in circulating BDNF in humans during exercise may originate in the contracting muscle cells and that BDNF may be a novel contraction-induced myokine. Accordingly, we aimed to investigate whether skeletal muscle would produce BDNF in response to exercise. In addition, since skeletal muscle contains many cell types, including motor neurons, we conducted in vitro experiments to determine whether muscle cells per se produced BDNF during contraction. Having shown that BDNF is indeed produced by skeletal muscle during contraction, we next sought to investigate whether BDNF can affect metabolic processes in skeletal muscle. We hypothesised that BDNF would be produced by skeletal muscle cells in response to contraction and then released into the circulation where it would enhance insulin action in other tissues such as liver and adipose tissue.

\section{Methods}

Human in vivo experiments Eight healthy, physically active but untrained men (mean \pm SD age: $25 \pm 4$ years, weight: $82 \pm$ $8 \mathrm{~kg}$, height: $181 \pm 1 \mathrm{~cm}$, BMI: $25 \pm 2 \mathrm{~kg} / \mathrm{m}^{2}$ ) were recruited to participate in the study, which was approved by the Ethics Committee of the University of Copenhagen. On the day of the experiment, the volunteers arrived at about 07:00 hours after an overnight fast. The participants performed $120 \mathrm{~min}$ of bicycle exercise at $60 \%$ of their predetermined $\dot{V} \mathrm{O}_{2}$ max 
followed by a $24 \mathrm{~h}$ recovery period. Muscle biopsy samples were obtained from vastus lateralis before exercise, immediately after exercise, and 3, 5, 8, 24, 48 and $72 \mathrm{~h}$ into recovery using a percutaneous needle biopsy technique with suction. Samples were snap frozen before being analysed for $B D N F$ mRNA and protein expression. Serum was obtained at the above mentioned time-points. Serum levels of BDNF were measured by ELISA (R\&D Systems, Wiesbaden-Nordenstadt, Germany). Platelet counts were determined by standard laboratory procedures.

Cell culture experiments $\mathrm{C} 2 \mathrm{C} 12$ cells (fewer than six passages) were purchased from the American Type Culture Collection (Manassas, VA, USA). Six-well culture plates were coated with extracellular matrix from Engelbreth-Holm swarm murine sarcoma (Sigma, Castle Hill, NSW, Australia). The C2C12 myoblasts were seeded in culture plates and grown in DMEM (low modified; SAFC Biosciences, Brooklyn, VIC, Australia) $+10 \%$ (vol./vol.) FBS $+1 \%$ penicillin/streptomycin. Differentiation of the myoblasts was induced by transferring cells to medium containing $2 \%$ (vol./vol.) horse serum rather than FBS when the myoblasts were about $90 \%$ confluent. Experimental treatments commenced after 5 days of differentiation when nearly all myoblasts had fused to form myotubes. Cells were cultured at $37^{\circ} \mathrm{C}$ in $5 \% \mathrm{CO}_{2}$ in a humidified chamber.

Next, to determine the effect of contraction on BDNF production in skeletal muscle cells, differentiated $\mathrm{C} 2 \mathrm{C} 12$ cells in six-well culture plates were placed in a custom-built chamber that allowed the cells to be electrically stimulated. Muscle cells were stimulated for $120 \mathrm{~min}$ (18 V; $1 \mathrm{~Hz} ; 24 \mathrm{~ms}$ ) at $37^{\circ} \mathrm{C}$ in $5 \% \mathrm{CO}_{2}$ in a humidified chamber according to methods previously described [26]. To verify that cells were contracting, we filmed the cells. We also measured the ATP and phosphocreatine $(\mathrm{PCr})$ concentration in unstimulated and stimulated cells using enzymatic assays with fluorometric detection [27] and measured lactate dehydrogenase $(\mathrm{LDH})$ release [27] from cells to verify that the contraction protocol was not causing cell membrane damage.

To examine whether BDNF affected phosphorylation $\left(\mathrm{Thr}^{172}\right.$ ) of AMPK and ACC $\beta$ ( $\left.\mathrm{Ser}^{79}\right)$, fully fused L6 myotubes were treated with recombinant human BDNF (rhBDNF; R\&D Systems, Minneapolis, MN, USA), which is known to cross-react with cells of rat origin [28]. Cells were treated with rhBDNF for 10 and $30 \mathrm{~min}$ at doses of 1 , 10 and $100 \mathrm{ng} / \mathrm{ml}$. Palmitate oxidation and glucose uptake experiments were performed as previously described [10]. For adenovirus experiments, myotubes were infected with a titred adenovirus containing control vector (AdGo/ GFP) or a dominant negative AMPK mutant [10]. In addition, L6 cells were also treated with $40 \mu \mathrm{mol} / 1$ of the AMPK inhibitor Compound C (Calbiochem, Kilsyth, VIC, Australia).
Ex vivo experiments Male Wistar rats (about $200 \mathrm{~g}$ ) were fed rat chow (6\% energy from fat, $21 \%$ from protein, $71 \%$ from carbohydrate; Gordon's Specialty Stock Feeds, Yanderra, NSW, Australia) and water, which were available ad libitum. All experimental procedures were in accordance with the National Health and Medical Research Council of Australia Guidelines on Animal Experimentation. To examine palmitate metabolism, the extensor digitorum longus muscle was carefully dissected into longitudinal strips and analysed for $\left[{ }^{14} \mathrm{C}\right]$ palmitate oxidation, as previously described [29] and contained in the Electronic supplementary material (ESM).

Electroporation experiments Electroporation experiments were conducted with permission from the Danish Animal Experiments Inspectorate. Animal experiments were performed on 8- to 10-week-old C57BL6/C mice (Taconic Tornbjerggaard, Lille Skensved, Denmark). The plasmids pTet-On, encoding the rtTA transactivator [30, 31], and pTetS, encoding the tS silencer [32], were both obtained from Clontech (Palo Alto, CA, USA). We used a pBI-BDNF encoding murine $B d n f$ under the control of an rtTAdependent promoter (Geneart, Regensburg, Germany). The $B d n f$ cDNA sequence was cleaned for immunogenic motifs, and codons were optimised to ensure optimal expression efficacy. Moreover, the plasmid contained a SV40 polyadenylation downstream of the $B d n f$ sequence. All DNA preparations were performed using Qiafilter Plasmid Maxiprep kits (Qiagen, Hilden, Germany), and the concentration and quality of the plasmid preparations were controlled by spectrophotometry and gel electrophoresis. The animals were anaesthetised $15 \mathrm{~min}$ prior to DNA electrotransfer by i.p. injection of Hypnorm $(0.4 \mathrm{ml} / \mathrm{kg}$; Janssen, Saunderton, UK) and Dormicum ( $2 \mathrm{mg} / \mathrm{kg}$; Roche, Basel, Switzerland). The plasmid solution $(2.5 \mu \mathrm{g}$ in $20 \mu \mathrm{l})$ was injected i.m. along the fibres into the right tibialis cranialis muscle using a $29 \mathrm{G}$ insulin syringe. Plate electrodes with $4 \mathrm{~mm}$ gap were fitted around the hind legs. Good contact between electrode and skin was ensured by hair removal and use of electrode gel. The electric field was applied using a Cliniporator (IGEA, Carpi, Italy), applying a combination of a high voltage $(800 \mathrm{~V} / \mathrm{cm}$ [applied voltage $=320 \mathrm{~V}$ ], $100 \mu \mathrm{s})$ pulse followed by a low voltage $(100 \mathrm{~V} / \mathrm{cm}$ [applied voltage $=40 \mathrm{~V}$ ], $400 \mathrm{~ms}$ ) pulse. Induction of gene expression was obtained by administering drinking water containing doxycycline (doxycycline hyclate; Sigma-Aldrich, Brondby, Denmark) at a concentration of $0.2 \mathrm{mg} / \mathrm{ml}$ in distilled water [33]. The control group was injected with saline and received doxycycline in the drinking water during the entire experiment. A third group of animals (sham) underwent electroporation of an empty vector. As no differences were reported when comparing the muscles of the control with the sham group, data from sham-treated muscles are reported. 
Analytical methods The RNA extraction, quantification and the mRNA abundance of $B D N F / B d n f$ and relevant controls were performed as previously described [34]. Real-time PCR was performed on an ABI PRISM 7900 sequence detector (PE Biosystems, Warrington, UK). Pre-developed TaqMan probe and primer sets for human GAPDH (Hs99999905_m1), human BDNF (Hs00380947_m1), mouse $B d n f\left(\mathrm{Mm} 00432069 \_\mathrm{m} 1\right)$ and eukaryotic 18S rRNA (4310893E) were obtained from Applied Biosystems (Scoresby, VIC, Australia). Muscle protein analyses were performed as previously described [10, 34]. Lysates were incubated overnight at $4{ }^{\circ} \mathrm{C}$ in blocking buffer containing a primary antibody against BDNF (Santa Cruz Biotechnology, Heidelberg, Germany; sc-546), phospho-AMPK (Thr ${ }^{172}$ ), phospho-ACC $\beta$ ( $\left.\mathrm{Ser}^{79}\right)$, phospho-extracellular signalregulated protein kinase (ERK)1/2 (p44/42 $\mathrm{Thr}^{202} / \mathrm{Tyr}^{204}$ ), ERK1/2, phospho-TrkB (Tyr $\left.{ }^{706 / 707}\right), \beta$-actin (Cell Signaling, Beverly, MA, USA) or $\alpha$-tubulin (Santa Cruz Biotechnology; sc-5546) at a final concentration of $1 \mu \mathrm{g} / \mathrm{ml}$. Membranes were washed three times in washing buffer and incubated for $60 \mathrm{~min}$ at room temperature with horseradish peroxidase-conjugated goat anti-rabbit (P0448; Dako, Glostrup, Denmark) at a 1:2,000 dilution in blocking buffer, followed by three $5 \mathrm{~min}$ washes in washing buffer. The protein bands were detected using Supersignal West Femto (Pierce, Rockford, IL, USA) and quantified using a CCD image sensor (ChemiDoc XRS; Biorad, Gladesville, NSW, Australia) and software (Quantity One; Biorad). BDNF in the media collected from contraction-stimulated experiments and in the plasma from $B d n f$-electroporated and control mice were analysed using a commercially available ELISA kit (BDNF Emax; Promega, Alexandria, NSW, Australia).

For muscle immunohistochemistry (IHC), muscle tissue was cut into $7 \mu \mathrm{m}$ consecutive sections on a cryostat, and the sections were immediately collected on glass slides. Sections were pre-incubated in $3 \% \mathrm{H}_{2} \mathrm{O}_{2}$ to quench endogenous peroxidase and followed by incubation in $10 \%$ (vol./vol.) goat serum to block unspecific background staining. Sections were incubated overnight at $4{ }^{\circ} \mathrm{C}$ with rabbit antihuman BDNF IgG diluted 1:400 (Santa Cruz Biotechnology, Santa Cruz, CA, USA; code sc-20981). The primary antibodies were detected using biotinylated anti-rabbit $\mathrm{IgG}$ diluted 1:400 (Sigma-Aldrich, St Louis, MO, USA; code B 3275 ) for $30 \mathrm{~min}$ at room temperature followed by streptavidin-peroxidase complex (StreptABCcomplex/HRP, code K377; Dakopatts, Glostrup, Denmark) for $30 \mathrm{~min}$ at room temperature, prepared according to the manufacturer's recommended dilutions. The immunoreaction was visualised using $0.015 \% \mathrm{H}_{2} \mathrm{O}_{2}$ in 3,3'-diaminobenzidine/TRIS-buffered saline for $10 \mathrm{~min}$ at room temperature. Afterwards, slides were dehydrated and mounted with cover glass for microscopy.
Statistics To examine whether there was an effect of exercise on the time-course of serum BDNF or platelets we used a two-way ANOVA for repeated measures. AUCs were compared by an unpaired $t$ test. In the cell culture experiments all data were analysed from three independent experiments and paired $t$ tests were used to statistically analyse the data.

\section{Results}

$B D N F$ is increased in human contracting skeletal muscle in vivo, but is not released into the circulation There were no differences in BDNF mRNA levels in the exercise cohort compared with the resting cohort (Fig. 1a). This was probably due to the fact that the BDNF mRNA levels demonstrated a marked inter-individual variation with peak mRNA levels between 5 and $8 \mathrm{~h}$ for the majority of the participants. As such, we calculated the AUC over time for both groups and showed a difference $(p<0.05)$ for the AUC when comparing the two groups. The antibody against BDNF protein recognises both the pro- and mature forms of BDNF. In all western blot experiments, rhBDNF was loaded into one lane as a positive control. In the human samples, the mature form of BDNF was recognised and the production appeared to increase progressively following exercise. At $24 \mathrm{~h}$ into recovery from exercise, BDNF protein levels were increased (about $50 \% ; p<0.05$ ) in the muscle homogenates (Fig. 1b, c). To confirm that this increase in BDNF expression was indeed increased within muscle fibres, we performed IHC experiments and showed that the increased BDNF production $24 \mathrm{~h}$ after exercise was indeed intramyocellular (Fig. 1d). We next aimed to ascertain whether the elevated BDNF in contracting skeletal muscle might be a source of circulating BDNF. Serum BDNF concentrations increased immediately following exercise, before returning to pre-exercise levels $60 \mathrm{~min}$ following the cessation of exercise (Fig. 2a). Since platelets are known to store and release BDNF [35], we examined the relationship between circulating BDNF and platelet count. The pattern of increase in platelet count (Fig. 2b) closely matched that for serum BDNF. In addition, the plasma levels of P-selectin, a marker of platelet activation, were also increased immediately following exercise (data not shown). Taken together, these results demonstrate that physical exercise increases circulating BDNF and that the increase may at least to some extent reflect in vivo release of BDNF from activated platelets. The kinetics of the exercise-induced elevation in serum BDNF levels failed to correlate with the increased production of BDNF in muscle $24 \mathrm{~h}$ after exercise, suggesting that the skeletal muscle is not a source of the increase in serum BDNF observed early into recovery from exercise. 
Fig. 1 BDNF is increased in contracting skeletal muscle in vivo. $B D N F$ mRNA levels (a) and protein production in muscle tissue measured by western blot $(\mathbf{b}, \mathbf{c})$ and IHC (d) at time-points ranging from 0 to $72 \mathrm{~h}$ after $2 \mathrm{~h}$ of ergometer bicycle exercise of the volunteers at $60 \%$ of $\dot{V} \mathrm{O}_{2 \max }$. ${ }^{*} p<0.05$, difference from pre-exercise (Pre-Ex). $n=8$ per time-point. For $B D N F$ mRNA studies, black columns indicate the exercised cohort and white columns the resting cohort. Values are means \pm SEM a

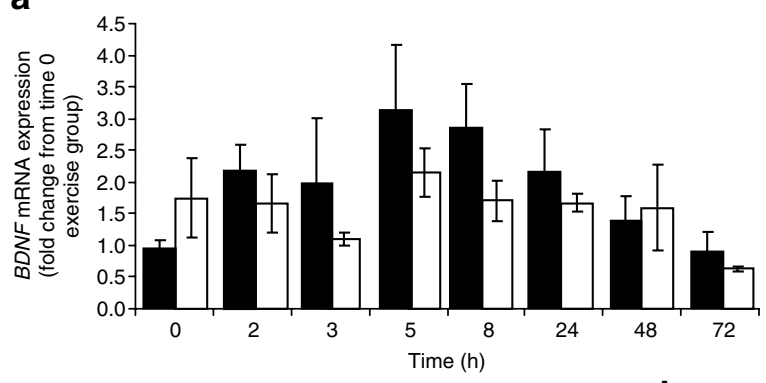

b

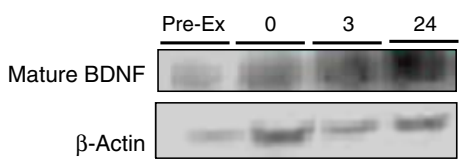

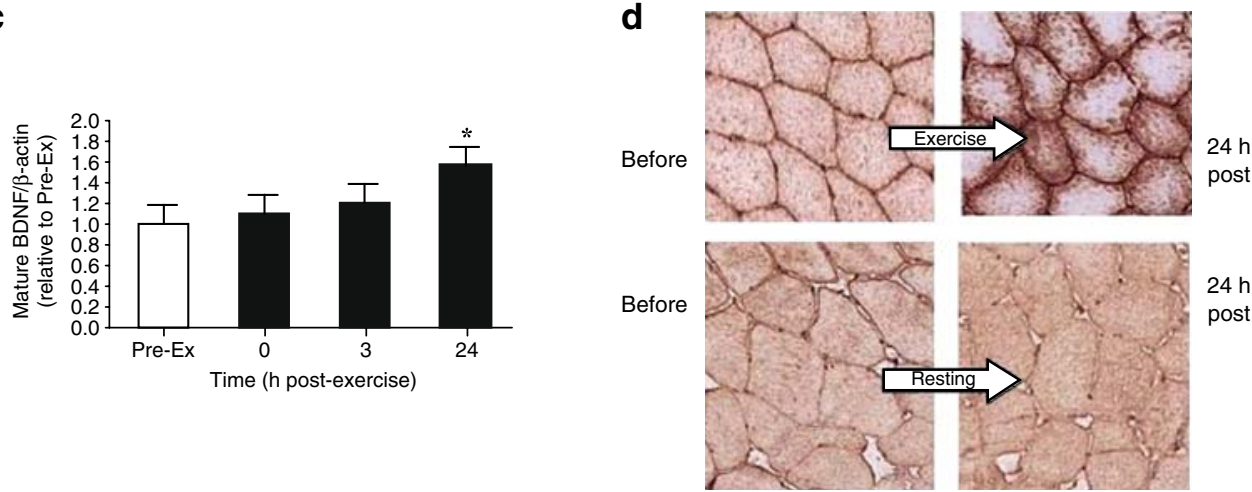

d
Muscle contraction increases BDNF levels in muscle cells in vitro Our IHC results suggested that the contractioninduced increase in BDNF protein level was increased in skeletal muscle cells. Since it was possible that BDNF was produced by other cell types within the skeletal muscle bed before being taken up by muscle cells, it was necessary to move to a cell culture model to determine whether skeletal muscle cells per se can increase BDNF levels when contracted. We established a cell culture system to contract differentiated $\mathrm{C} 2 \mathrm{C} 12$ myotubes in vitro. We were able to visualise series contraction during the application of the electrical stimulus (ESM video clip). To demonstrate that the cells were undergoing metabolic stress characteristic of in vivo prolonged low-intensity muscle contraction, rather than cell damage, we first showed that PCr, but not ATP, stores were decreased by contraction (Fig. 3a). We also showed that contraction did not increase LDH release from cells into the media (Fig. 3b). In addition, in line with previous studies from our laboratory $[34,36]$, contraction increased phosphorylation $\left(\mathrm{Thr}^{180} / \mathrm{Tyr}^{182}\right)$ of $\mathrm{p} 38$ mitogenactivated protein kinase, heat shock protein 70 protein production and IL6 mRNA (data not shown) and the phosphorylation of AMPK ( $\mathrm{Thr}^{172}$ ) (Fig. 3c). In addition, muscle contraction increased $B d n f$ mRNA levels compared with non-contracted cells (Fig. 3d). Moreover, such a treatment increased both the pro- and mature BDNF protein levels immediately after the contraction protocol (Fig. 3e, f). These data demonstrate that BDNF is a contractioninduced protein. We were unable to detect any differences in BDNF release in the media of control compared with contraction-treated cells (data not shown).
Fig. 2 Exercise results in immediate increases in serum BDNF levels and platelet numbers in volunteers. Serum BDNF levels (a) and platelet counts (b) are shown at times in relation to $2 \mathrm{~h}$ of ergometer bicycle exercise at $60 \%$ of $\dot{V} \mathrm{O}_{2 \max }$ (hatched columns) or in resting controls (white columns). ${ }^{*} p<0.05$, difference from baseline. $n=10$ per time-point. Values are means \pm SEM 

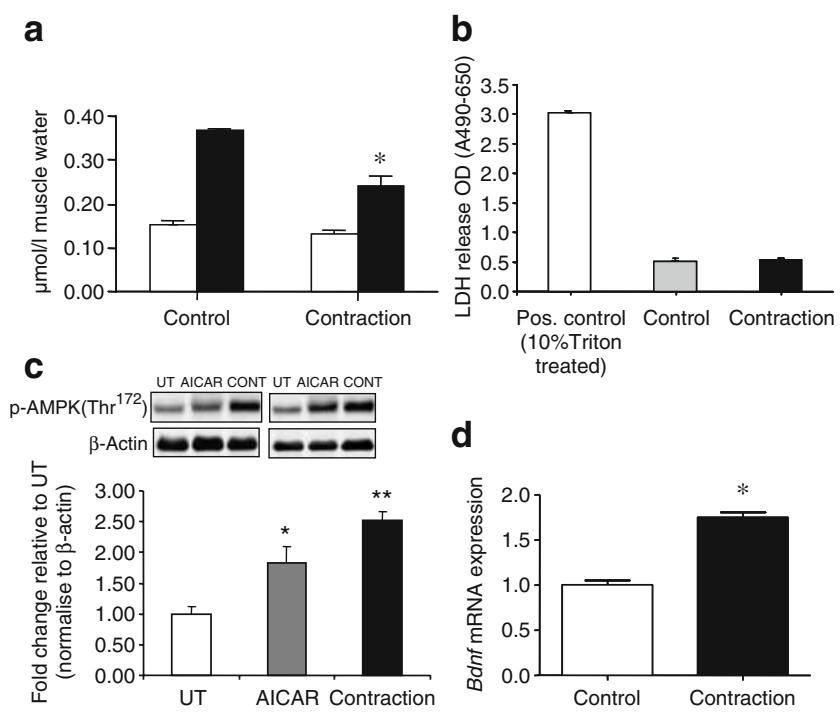

e
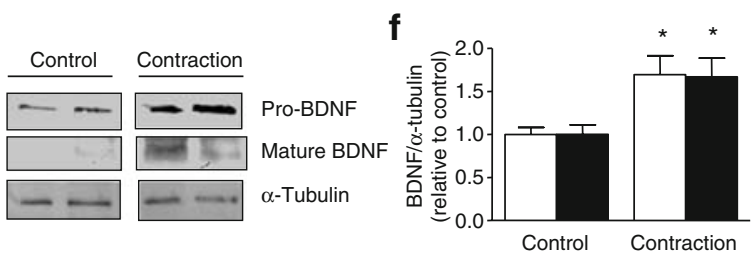

Fig. $3 B d n f$ mRNA and protein expression is increased in contracting muscle cells. ATP (white columns) and PCr (black columns) (a), LDH release (b), phosphorylation (p-) of AMPK (c), Bdnf mRNA expression (d), representative immunoblot (e) and quantification (f) of pro-BDNF (white columns) and mature BDNF (black columns) protein levels in unstimulated (Control) or electrically stimulated $\mathrm{C} 2 \mathrm{C} 12$ cells (Contraction; $18 \mathrm{~V}, 1 \mathrm{~Hz}, 24 \mathrm{~ms}$ ) at $37^{\circ} \mathrm{C}, 5 \% \mathrm{CO}_{2}$ for 120 min. UT, untreated. ${ }^{*} p<0.05$ for difference from $\mathrm{CON} ; n=6$ per group. Values are means \pm SEM

BDNF increases fat oxidation in an AMPK-dependent manner in L6 myotubes Having established that BDNF was a contraction-induced protein, we next sought to determine whether BDNF affected signalling pathways associated with fat oxidation in skeletal muscle. This hypothesis was based on the observation that BDNF reduces obesity in diabetic mice [18]. AMPK phosphorylates ACC $\beta$ resulting in inhibition of ACC activity, which in turn leads to a decrease in malonyl-CoA content, relieving inhibition of carnitine palmitoyl transferase 1 and increasing fatty acid oxidation (FAO). Accordingly, we treated L6 myotubes with 1,10 and $100 \mathrm{ng} / \mathrm{ml}$ BDNF for 10 and $30 \mathrm{~min}$ and quantified the phosphorylation of AMPK (Fig. 4a, b) and ACC $\beta$ (Fig. 4a, c). We showed that at the two higher doses, BDNF markedly phosphorylated $\mathrm{ACC} \beta$, while a similar effect was seen for phospho-AMPK at the higher dose. The lack of effect of phospho-AMPK at $10 \mathrm{ng} / \mathrm{ml}$ was unexpected since phospho-ACC $\beta$ was increased. The time-dependent effects were transient as no differences were seen in phospho-AMPK or phospho$\mathrm{ACC} \beta$ at $30 \mathrm{~min}$ (data not shown), with the effects present a

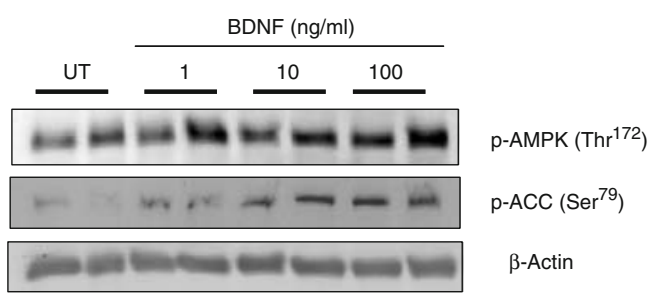

b

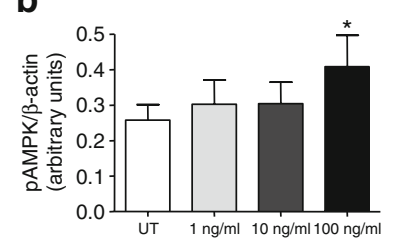

d

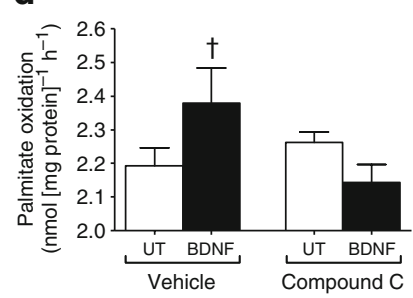

C

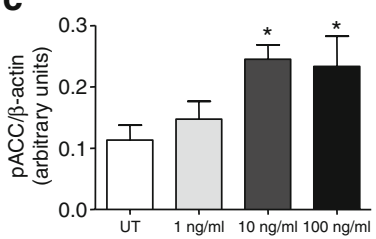

e

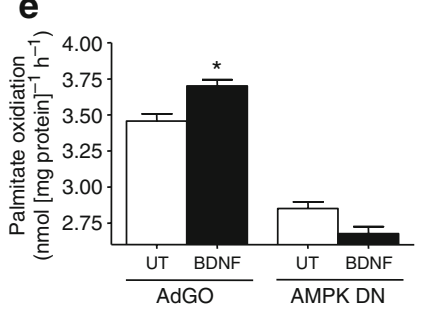

Fig. 4 BDNF increases phosphorylation (p-) of AMPK, its downstream target ACC $\beta$ (ACC) and FAO in an AMPK-dependent manner in L6 myotubes. Representative immunoblots (a) and quantification of phosphorylation of AMPK $\left(\mathrm{Thr}^{172}\right)$ (b) and ACC $\beta\left(\mathrm{Ser}^{79}\right)$ (c) in L6 myotubes treated for $10 \mathrm{~min}$ with 1,10 and $100 \mathrm{ng} / \mathrm{ml} \mathrm{rhBDNF}$. Palmitate oxidation in L6 myotubes treated with the AMPK inhibitor Compound $\mathrm{C}$ or vehicle control (d) or infected with an AMPK dominant negative (AMPK DN) or control virus (AdGO) $(\mathbf{e}) . * p<0.05$ for difference from untreated (UT) cells. ${ }^{\dagger} p<0.05$ for difference from BDNF $(10 \mathrm{ng} / \mathrm{ml})+$ Compound C-treated cells. $n=6$ per group. Values are means \pm SEM

at only 10 min (Fig. 4a-c). Next, to determine if fat oxidation was enhanced in these cells and whether any such increase was due to activation of the AMPK pathway, we performed labelled palmitate oxidation experiments. Irrespective of whether cells were treated with PBS (Fig. 4d) or infected with a control virus (AdGO) (Fig. 4e) treatment of cells with BDNF enhanced fat oxidation. However, when cells were treated with the AMPK inhibitor Compound $\mathrm{C}$ or infected with an AMPK dominant negative adenovirus, the BDNF-induced increase in fat oxidation was completely abrogated (Fig. 4d, e) demonstrating that the BDNF-induced increase in FAO is AMPK-dependent. Finally, we tested whether BDNF promoted glucose uptake in L6 myotubes. Unlike insulin treatment, BDNF failed to increase glucose uptake above those levels seen in vehicletreated cells (fold change from vehicle: vehicle $=1 \pm 0.04$; insulin at $100 \mathrm{nmol} / \mathrm{l}=2.32 \pm 0.072 ; \mathrm{BDNF}$ at $10 \mathrm{ng} / \mathrm{ml}=$ $0.94 \pm 0.071$; and insulin $+\mathrm{BDNF}=1.99 \pm 0.185$ ).

BDNF increases phosphorylation of AMPK and its downstream target $A C C \beta$ and results in enhanced fat oxidation 
in intact skeletal muscle ex vivo Having established that BDNF enhanced AMPK signalling and fat oxidation in vitro, we next sought to determine whether this effect was also seen in intact rodent skeletal muscle. Accordingly, experiments were performed in extensor digitorum longus muscle obtained from rats and dissected into longitudinal strips from tendon to tendon. Incubating these muscle strips in BDNF resulted in increased phospho-AMPK at $90 \mathrm{~min}$ (Fig. 5a, c) and phospho-ACC $\beta$ at 30 and 90 min (Fig. 5b, c). Moreover, treatment of muscle strips with BDNF for $120 \mathrm{~min}$ resulted in enhanced palmitate oxidation (Fig. 5d). It should also be noted that while both BDNF and the positive control 5-aminoimidazole-4-carboxamide 1- $\beta$-D-ribofuranoside (AICAR) increased ${ }^{14} \mathrm{C}$ in the $\mathrm{CO}_{2}$ fraction, this was not seen in the acid soluble metabolite fraction, indicating complete oxidation of the label.

\section{Skeletal muscle overproduction of BDNF in vivo results} in ERK, TrkB and ACC $\beta$ phosphorylation, but does not increase circulating BDNF levels Results from our human exercise studies and cell culture experiments suggested that BDNF was produced by muscle cells during contraction, but was not released into the circulation or media. These data, coupled with the in vitro and ex vivo observations that BDNF enhanced AMPK signalling and fat oxidation, suggested that BDNF was produced by skeletal muscle

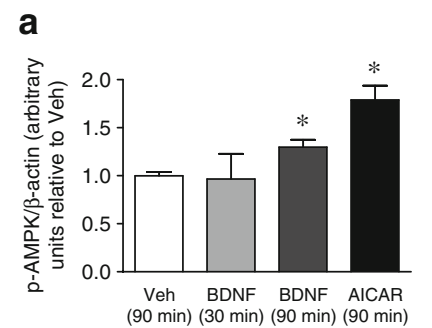

C

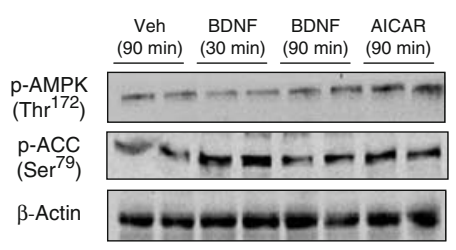

\section{b}
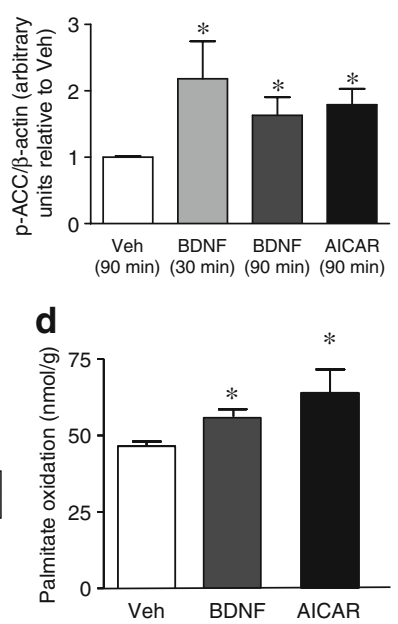

Fig. 5 BDNF increases phosphorylation (p-) of AMPK and its downstream target ACC $\beta$ (ACC) and enhances fat oxidation in isolated intact rat skeletal muscle. Quantification of phosphorylation of AMPK $\left(\mathrm{Thr}^{172}\right)$ (a) and $\mathrm{ACC} \beta\left(\mathrm{Ser}^{79}\right)$ (b) and representative immunoblots (c) and palmitate oxidation (d) in isolated rat extensor digitorum longus muscles treated for 30 and $90 \mathrm{~min}(\mathbf{a}-\mathbf{c})$ and $120 \mathrm{~min}$ (d) with $10 \mathrm{ng} / \mathrm{ml} \mathrm{rhBDNF}{ }^{*} p<0.05$ for difference from untreated vehicle control muscles (Veh). $n=5$ rats per group. Values are means \pm SEM cells to act locally. To test this hypothesis in vivo, we transiently overproduced BDNF in skeletal muscle using the in vivo electroporation technique. We observed marked overproduction of both the pro- and mature form of BDNF (Fig. 6a, b). Despite this level of overproduction, we did not observe any differences in plasma BDNF when we compared these animals with saline-treated control animals (data not shown), providing further evidence that BDNF exerts its action locally and is not released into the circulation when intramuscular production is increased. We next addressed whether BDNF activated intracellular signalling in an autocrine and/or paracrine fashion. BDNF signals via a specific receptor tyrosine kinase (TrkB). Upon BDNF binding, TrkB is phosphorylated $\left(\mathrm{Tyr}^{705 / 706}\right)$ resulting in a signalling cascade that includes phosphorylation of ERK $\left(\mathrm{Thr}^{202} / \mathrm{Tyr}^{204}\right)$. Overproduction of BDNF resulted in increased phosphorylation of both ERK (Fig. 6c) and TrkB (Fig. 6d, e) compared with sham-electroporated muscle. These data suggest that BDNF may act in an autocrine and/ or paracrine fashion in skeletal muscle. Moreover, overpro-

a

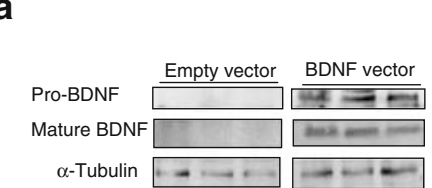

C
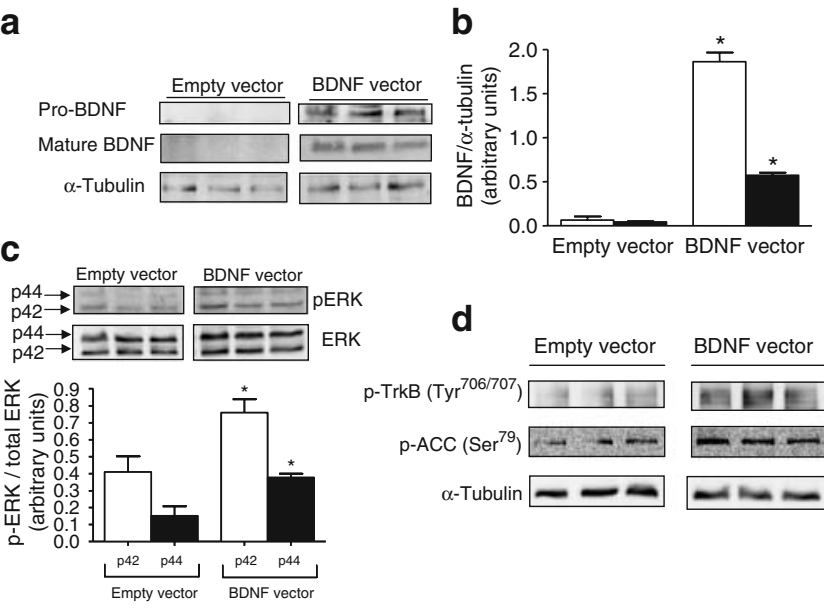

d

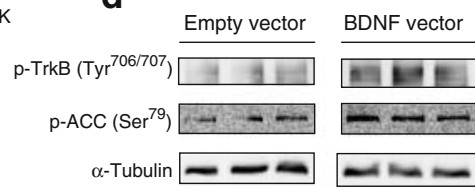

e

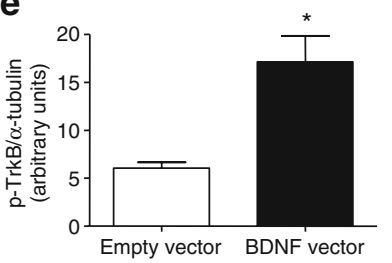

f

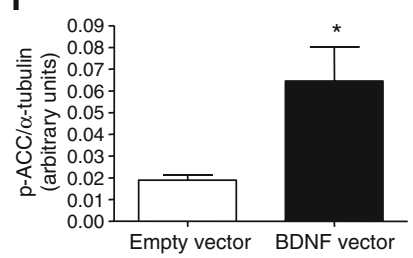

Fig. 6 Mouse skeletal muscle overexpression of BDNF in vivo increases ERK, TrkB and ACC $\beta$ (ACC) phosphorylation (p-). Representative immunoblots (a) and quantification (b) of pro-BDNF (white columns) and mature BDNF (black columns) protein expression. Representative immunoblots and quantification of phosphorylation of ERK ( $\mathrm{Thr}^{202} / \mathrm{Tyr}^{204}$ ) (c), representative immunoblots (d) and quantification of phosphorylation of $\mathrm{TrkB}\left(\mathrm{Tyr}^{706 / 707}\right)$ (e) and $\mathrm{ACC} \beta$ $\left(\mathrm{Ser}^{79}\right)$ (f) in skeletal muscle that underwent in vivo electroporation with an empty vector or vector containing $B d n f$ plasmid. ${ }^{*} p<0.05$ for difference from empty vector. $n=3$ mice per group. Values are means \pm SEM 
duction of BDNF in skeletal muscle in vivo markedly increased ACC $\beta$ phosphorylation (Fig. 6d, f).

\section{Discussion}

Taken together, our data demonstrate that BDNF is a protein produced in skeletal muscle cells that is increased by contraction to enhance fat oxidation in an AMPKdependent fashion, most probably by acting in an autocrine and/or paracrine manner within skeletal muscle. Hence, we have identified BDNF as being a novel contraction-induced protein that may contribute to the multiple health benefits associated with exercise, possibly by enhancing fat oxidation in skeletal muscle.

A novel and important finding from the present study is that skeletal muscle cells per se produced BDNF and that this production is increased following contraction. Recent studies have demonstrated that $B d n f$ mRNA increases in the contracting skeletal muscle of rodents [22, 23], but these studies concluded that the likely source of the BDNF was neurons within the skeletal muscle beds. In addition, in a recent study, the mRNA of $B d n f$ was shown to be expressed in murine skeletal muscle homogenates and that this was increased by inhibition of histone deacetylases [24], but this study too could not conclude that the muscle cells produced the BDNF. By conducting muscle cell culture experiments, we show that $\mathrm{C} 2 \mathrm{C} 12$ murine cells not only produce $\mathrm{BDNF}$, but that this production can be increased by contraction.

Recently, we demonstrated a strong association between low plasma BDNF and type 2 diabetes on the one hand and both obesity and insulin resistance on the other [37]. The latter findings are supported by animal studies, which demonstrate an insulin-sensitising effect of BDNF [15-17]. Importantly, we have recently demonstrated that a different neurotrophin, namely ciliary neurotrophic factor (CNTF) can increase insulin sensitivity and decrease obesity by acting on both central [38] and peripheral [39, 40] tissues. Here we provide a potential mechanism as to how BDNF may improve metabolic disease, since we show both in vitro and in intact muscle ex vivo that, like CNTF, BDNF activates AMPK signalling and enhances FAO. Moreover, we demonstrate that the BDNF-induced increase in FAO is AMPK-dependent, at least in vitro, since either infection of cells with an AMPK dominant negative adenovirus (Fig. 4e) or treatment of cells with the AMPK inhibitor Compound C (Fig. 4d), completely attenuated the increase. It should be noted that during exercise in humans, fat oxidation is increased at the onset of contraction while the increase in BDNF in skeletal muscle does not occur until well into recovery. Therefore, it is clear that BDNF plays no role in mediating contraction-induced increases in fat oxidation. Nonetheless, our data raise the possibility that ligands that activate TrkB [41] are a possible therapeutic target for metabolic disease.

Unlike the cytokine IL-6, which is upregulated by muscle contractions, leading to altered liver [9] and adipose tissue [42] metabolism, our data suggest that contractioninduced muscle-derived BDNF does not act in a hormonelike manner. We showed that circulating levels of BDNF increased immediately after exercise and did not correlate with the elevated muscle-derived BDNF $24 \mathrm{~h}$ after exercise. In addition, we were unable to detect any BDNF in the media from cells that underwent contraction, even though such an intervention increased BDNF protein production. Moreover, when we overproduced the mature form of BDNF in skeletal muscle in vivo more than ten-fold via electroporation, we did not detect any increase in systemic BDNF concentration compared with control animals. It is more likely that muscle-derived BDNF works in an autocrine and/or paracrine manner within the skeletal muscle bed. This hypothesis is plausible since overproduction of BDNF resulted in marked ERK (Fig. 6c) and TrkB (Fig. 6d, e) phosphorylation, which is indicative of signalling through TrkB, which is produced in skeletal muscle and myotubes [43]. In addition, in our electroporation experiments, we detected increases in both the proand mature form of BDNF (Fig. 6a, b). It is well known that pro-BDNF can be processed into mature BDNF by several matrix metalloproteinases and thereby regulate activation of TrkB either by autophosphorylation or via an interaction with a neighbouring cell [44]. Consistent with BDNF treatment of cells and skeletal muscle ex vivo, overproduction of BDNF also resulted in phosphorylation of ACC $\beta$. Whether this effect was due to paracrine/ autocrine signalling or due to a direct intracellular signalling event requires further clarification. It must be acknowledged, however, that the contraction-induced increase in BDNF both in vivo (Fig. 1) and in vitro (Fig. 3) was relatively modest, whereas we increased BDNF several fold with electroporation (Fig. 6). Therefore, whether BDNF plays an important role in vivo is unclear.

In summary, we have identified BDNF as being a novel contraction-induced muscle cell-derived protein that can increase fat oxidation in skeletal muscle in an AMPKdependent fashion. Our data, therefore, raise the possibility that BDNF analogues could be used as a possible therapy to treat metabolic disease.

Acknowledgements B. Starup Mentz, R. Rousing and H. Villumsen are acknowledged for their technical assistance. We acknowledge the assistance of J. Pringle in developing the contraction apparatus. The Cellular and Molecular Metabolism Laboratory is supported by grants from the National Health and Medical Research Council of Australia (NHMRC), the Australian Research Council and the Diabetes Australia Research Trust (DART). This study was specifically 
supported, in part, by a DART grant awarded to V. B. Matthews. C. R. Bruce is a Peter Doherty post-doctoral fellow, V. B. Matthews and M. J. Watt are R. D. Wright Career Development Fellows, and M. A. Febbraio a Principal Research Fellow of the NHMRC. The Centre of Inflammation and Metabolism is supported by a grant from the Danish National Research Foundation (DG 02-512-555). The Copenhagen Muscle Research Centre is supported by grants from the University of Copenhagen and the Faculty of Science and Health Sciences. This study was further supported by the Novo Nordisk Foundation, the Lundbeck Foundation, the Beckett Foundation, Lægevidenskabens Fremme, the Copenhagen Hospital Corporation, the Danish Medical Research Foundation (Grant 504-14) and the Commission of the European Communities (Contract No. LSHM-CT-2004-005272 EXGENESIS).

Duality of interest The authors declare that there is no duality of interest associated with this manuscript.

\section{References}

1. Paffenbarger RS Jr, Hyde RT, Wing AL, Lee IM, Jung DL, Kampert JB (1993) The association of changes in physicalactivity level and other lifestyle characteristics with mortality among men. New Engl J Med 328:538-545

2. Richter EA, Garetto LP, Goodman MN, Ruderman NB (1982) Muscle glucose metabolism following exercise in the rat: increased sensitivity to insulin. J Clin Invest 69:785-793

3. Wojtaszewski JF, Hansen BF, Gade J et al (2000) Insulin signaling and insulin sensitivity after exercise in human skeletal muscle. Diabetes 49:325-331

4. King DS, Dalsky GP, Clutter WE et al (1988) Effects of exercise and lack of exercise on insulin sensitivity and responsiveness. J Appl Physiol 64:1942-1946

5. Pedersen BK, Febbraio MA (2005) Muscle-derived interleukin-6: a possible link between skeletal muscle, adipose tissue, liver, and brain. Brain Behav Immun 19:371-376

6. Febbraio MA, Pedersen BK (2005) Contraction-induced myokine production and release: is skeletal muscle an endocrine organ? Exerc Sport Sci Rev 33:114-119

7. Febbraio MA, Pedersen BK (2002) Muscle-derived interleukin-6: mechanisms for activation and possible biological roles. FASEB J 16:1335-1347

8. Pedersen BK, Steensberg A, Fischer C et al (2003) Searching for the exercise factor-is IL-6 a candidate. J Muscle Res Cell Motil 24:113-119

9. Febbraio MA, Hiscock N, Sacchetti M, Fischer CP, Pedersen BK (2004) Interleukin-6 is a novel factor mediating glucose homeostasis in skeletal muscle contraction. Diabetes 53:1643-1648

10. Carey AL, Steinberg GR, Macaulay SL et al (2006) Interleukin-6 increases insulin-stimulated glucose disposal in humans and glucose uptake and fatty acid oxidation in vitro via AMPactivated protein kinase. Diabetes 55:2688-2697

11. Izumiya Y, Hopkins T, Morris C et al (2008) Fast/glycolytic muscle fiber growth reduces fat mass and improves metabolic parameters in obese mice. Cell Metab 7:159-172

12. Handschin C, Choi CS, Chin S et al (2007) Abnormal glucose homeostasis in skeletal muscle-specific PGC-1alpha knockout mice reveals skeletal muscle-pancreatic beta cell crosstalk. J Clin Invest 117:3463-3474

13. Handschin C, Spiegelman BM (2008) The role of exercise and PGC1alpha in inflammation and chronic disease. Nature 454:463469

14. Snider WD (1998) How do you feel? Neurotrophins and mechanotransduction. Nat Neurosci 1:5-6
15. Ono M, Ichihara J, Nonomura T et al (1997) Brain-derived neurotrophic factor reduces blood glucose level in obese diabetic mice but not in normal mice. Biochem Biophys Res Commun 238:633-637

16. Tonra JR, Ono M, Liu X et al (1999) Brain-derived neurotrophic factor improves blood glucose control and alleviates fasting hyperglycemia in C57BLKS-leprdb/leprdb mice. Diabetes 48:588-594

17. Nakagawa T, Tsuchida A, Itakura $Y$ et al (2000) Brain-derived neurotrophic factor regulates glucose metabolism by modulating energy balance in diabetic mice. Diabetes 49:436-444

18. Tsuchida A, Nonomura T, Nakagawa $T$ et al (2002) Brain-derived neurotrophic factor ameliorates lipid metabolism in diabetic mice. Diabetes Obes Metab 4:262-269

19. Ferris LT, Williams JS, Shen CL (2007) The effect of acute exercise on serum brain-derived neurotrophic factor levels and cognitive function. Med Sci Sports Exerc 39:728-734

20. Rojas Vega S, Strüder HK, Vera Wahrmann B, Schmidt A, Bloch W, Hollmann W (2006) Acute BDNF and cortisol response to low intensity exercise and following ramp incremental exercise to exhaustion in humans. Brain Res 1121:59-65

21. Gold SM, Schulz KH, Hartmann S et al (2003) Basal serum levels and reactivity of nerve growth factor and brain-derived neurotrophic factor to standardized acute exercise in multiple sclerosis and controls. J Neuroimmunol 138:99-105

22. Dupont-Versteegden EE, Houlé JD, Dennis RA et al (2004) Exercise-induced gene expression in soleus muscle is dependent on time after spinal cord injury in rats. Muscle Nerve 29:73-81

23. Gómez-Pinilla F, Ying Z, Opazo P, Roy RR, Edgerton VR (2001) Differential regulation by exercise of BDNF and NT-3 in rat spinal cord and skeletal muscle. Eur J Neurosci 13:1078-1084

24. Avila AM, Burnett BG, Taye AA et al (2007) Trichostatin A increases SMN expression and survival in a mouse model of spinal muscular atrophy. J Clin Invest 117:659-671

25. McGee SL, Hargreaves M (2004) Exercise and myocyte enhancer factor 2 regulation in human skeletal muscle. Diabetes 53:1208-1214

26. Fujita H, Nedachi T, Kanzaki M (2007) Accelerated de novo sarcomere assembly by electric pulse stimulation in $\mathrm{C} 2 \mathrm{C} 12$ myotubes. Exp Cell Res 313:1853-1865

27. Lowry OH, Passonneau JV (1972) A flexible system of enzymatic analysis. Academic, New York

28. Chen H, Weber AJ (2004) Brain derived neurotrophic factor reduces TrkB protein and mRNA in the normal retina and following optic nerve crush in adult rats. Brain Res 1011:99-106

29. Dyck DJ, Peters SJ, Glatz J et al (1997) Functional differences in lipid metabolism in resting skeletal muscle of various fiber types. Am J Physiol 272:E340-E351

30. Gossen M, Bujard H (1992) Tight control of gene expression in mammalian cells by tetracycline-responsive promoters. Proc Natl Acad Sci U S A 89:5547-5551

31. Kistner A, Gossen M, Zimmermann F et al (1996) Doxycyclinemediated quantitative and tissue-specific control of gene expression in transgenic mice. Proc Natl Acad Sci U S A 93:10933-10938

32. Lamartina S, Roscilli G, Rinaudo CD et al (2002) Stringent control of gene expression in vivo by using novel doxycyclinedependent trans-activators. Hum Gene Ther 13:199-210

33. Højman P, Eriksen J, Gehl J (2007) Tet-On induction with doxycycline after gene transfer in mice: sweetening of drinking water is not a good idea. Anim Biotechnol 18:183-188

34. Chan MHS, McGee SL, Watt MJ, Hargreaves M, Febbraio MA (2004) Altering dietary nutrient intake that reduces glycogen content leads to phosphorylation of nuclear p38 MAP kinase in human skeletal muscle: association with IL-6 gene transcription during contraction. FASEB J 18:1785-1787

35. Fujimura H, Altar CA, Chen R et al (2002) Brain-derived neurotrophic factor is stored in human platelets and released by agonist stimulation. Thromb Haemost 87:728-734 
36. Febbraio MA, Steensberg A, Walsh R et al (2002) Reduced muscle glycogen availability elevates HSP72 in contracting human skeletal muscle. J Physiol 538:911-917

37. Krabbe KS, Nielsen AR, Krogh-Madsen R et al (2007) Brainderived neurotrophic factor (BDNF) and type 2 diabetes. Diabetologia 50:431-438

38. Steinberg GR, Watt MJ, Fam BC et al (2006) Ciliary neurotrophic factor suppresses hypothalamic AMPK signaling in leptin resistant obese mice. Endocrinology 147:3906-3914

39. Watt MJ, Dzamko N, Thomas W et al (2006) CNTF reverses obesity-induced insulin resistance by activating skeletal muscle AMPK. Nat Med 12:541-548

40. Watt MJ, Hevener A, Lancaster GI, Febbraio MA (2006) Ciliary neurotrophic factor prevents acute lipid-induced insulin resistance by attenuating ceramide accumulation and phosphorylation of JNK in peripheral tissues. Endocrinology 147:2077-2085

41. Kaplan DR, Martin-Zanca D, Parada LF (1991) Tyrosine phosphorylation and tyrosine kinase activity of the trk protooncogene product induced by NGF. Nature 350:158-160

42. van Hall G, Steensberg A, Sacchetti M et al (2003) Interleukin-6 stimulates lipolysis and fat oxidation in humans. J Clin Endocrinol Metab 88:3305-3310

43. Tsuchida A, Nakagawa T, Itakura $Y$ et al (2001) The effects of brain-derived neurotrophic factor on insulin signal transduction in the liver of diabetic mice. Diabetologia 44:555-566

44. Ethell IM, Ethell DW (2007) Matrix metalloproteinases in brain development and remodeling: synaptic functions and targets. J Neurosci Res 85:2813-2823 